ISSN 1822-427X/eISSN 1822-4288 2021 Volume 16 Issue 3: 111-130 https://doi.org/10.7250/bjrbe.2021-16.534
THE BALTIC JOURNAL

\title{
A COST-BENEFIT ANALYSIS \\ OF THE INSTALLATION OF AN AUTOMATIC INCIDENT DETECTION SYSTEM IN VILNIUS
}

\author{
ALDONA JARAŠŪNIENE' ${ }^{1 *}$, MARTA NOVIKOVA ${ }^{2}$ \\ ${ }^{1}$ Department of Logistics and Transport Management, \\ Vilnius TECH, Vilnius, Lithuania \\ ${ }^{2}$ Department of Economics Engineering, Vilnius TECH, Vilnius, Lithuania
}

Received 5 October 2020; accepted 22 March 2021

\begin{abstract}
A well-functioning transport network is a key element of a successful economy. One of the biggest problems in transportation is the large number of vehicles, which leads to congestion. Traffic congestion negatively influences the social and economic environment: it creates pollution and causes many accidents. A variety of innovative technologies are being applied in all areas. Different countries use Intelligent Transport Systems to create a safer, more efficient, and sustainable transport system to monitor and manage traffic flow. The application of Intelligent Transport Systems helps solve problems in the transport sector: Intelligent Transport Systems helps manage traffic flows, reduce accident rates, environmental pollution, and inform drivers and passengers about the traffic situation. Consequently, Intelligent Transport System improves the efficiency of the transport system, the quality of services, increases mobility, reduces energy consumption, and reduces the negative impact of vehicles on the environment. As reported by the Department of Statistics data in Lithuania, the number of road vehicles in the Vilnius region increases every year. Traffic accidents remain constant, and long-lasting traffic jams occur. Due to these reasons, Vilnius and its residents incur economic
\end{abstract}

\footnotetext{
* Corresponding author. E-mail: aldona.jarasuniene@vilniustech.lt

Aldona JARAŠŪNIENĖ (ORCID ID 0000-0002-9804-0064)

Marta NOVIKOVA (ORCID ID 0000-0002-0388-3166) 
costs, and the transport system is used inefficiently. This article examines the importance of Intelligent Transport System application in solving congestion, pollution and accidents in Vilnius. A cost-benefit analysis of the Automatic Incident Detection System installation in Vilnius is performed.

Keywords: Automatic Incident Detection (AID), congestion, Intelligent Transport (IT) system, safety, statistic data, transport system.

\section{Introduction}

The transport system consists of transport infrastructure, vehicles and transport facilities: passengers and freight (Ambrazevičius, 2008; Rodrigue \& Notteboom, 2020). The transport system provides an opportunity to use existing roads efficiently, provide cheaper services to consumers, plan the number of vehicles properly, and improve the existing legal framework in the light of ongoing changes (Ambrazevičius, 2008). The transport system must be safe, maintainable, open, and accessible (National Research Council..., 2002). The transport system must be designed and organised to meet consumer needs efficiently and comfortably freight and people (National Research Council..., 2002). A large part of the transport system is a public place that all passengers use (National Research Council..., 2002).

Statista $\mathrm{GmbH}$ data present that the most popular vehicle is a personal car, i.e. about 78.3 million cars are sold every year from 2016 to 2018, and 72 million cars were produced. Many vehicles have led to specific problems in the transport system, such as increased accident rate, congestion, the negative impact of transport on the environment, low public interest in public transport. Sumra et al. (2013) state that road traffic crashes increase congestion, and poor weather conditions worsen. Consequently, a more efficient and safer transport system is needed. An Intelligent Transport system is an effective tool for solving problems in the transport system (Sumra et al., 2013).

\section{Theoretical aspects of the application of Intelligent Transport systems}

The primary function of the IT system is to improve the performance of the transport system, help manage the infrastructure for making better decisions, and create a transport system that suits users (Hofmeister \& Kadner, 2011; Paulauskas et al., 2011). For this reason, IT systems consist of systems responsible for collecting, processing, and integrating information and systems responsible for delivering results 
to users (Perallos et al., 2015). Intelligent Transport systems reduce accident rates, encourage more people to choose public transport by making it better. Intelligent Transport systems have the advantage of being able to use advanced management technologies to improve the performance of the transport system, as well as the ability to change and adapt to a changing environment, to perform many different functions and always to operate quickly and efficiently (Janušová \& Čičmancová, 2016). Intelligent Transport systems provide benefits if the system is entirely open, able to work with data from all available sources and provide services to potential customers (Janušová \& Čičmancová, 2016). Intelligent Transport systems positively impact infrastructure, vehicles, drivers, or passengers (Perallos et al., 2015). They improve the efficiency of the infrastructure and transport system, increase safety, help to spread information more quickly in the modern world, and make it easier and faster for people to travel (Haseeb, 2017).

Innovations are being implemented rapidly, and the world is equipped with various IT systems that offer a number of benefits. Intelligent Traffic Management Systems traffic lights adaptive to traffic flows, systems for programming green transport corridors (Sotra, 2017). It is also a traffic flow sensor, electronic scoreboards for information on traffic, speed measuring devices, navigation, maps, electronic toll collection, electronic payment systems, emergency vehicle notification systems, collision warning and avoidance systems, real-time parking management systems, autonomous vehicles, car, bicycle, scooter rental platforms, Global Positioning System (GPS), video surveillance cameras (AIndra Labs, 2019).

Integrated motorway traffic flow control considering Vehicle Automation and Communication Systems (VACSs) is important to analyse. Automation and Communication Systems act both as sensors (providing information on traffic conditions) and as actuators, permitting the deployment of ramp metering, variable speed limits, and lane changing control (Roncoli et al., 2015).

Congestion, accidents, and pollution issues due to transportation are becoming more severe due to the tremendous increase in various travel demands, including vehicular traffic, public transportation, freight, and even pedestrian traffic. Intelligent Transport systems have been developed to resolve issues that integrate a broad range of systems, including sensing, communication, information dissemination, and traffic control. Three components are necessary for any IT system to perform its functions: data collection, data analysis, and data and information transmission (Sumalee \& Ho, 2018).

Researchers Liu et al. (2020) argue that the development and application of IT systems have significantly improved quality of life of the Installation of an Automatic Incident Detection System in Vilnius 
and provided convenience in many respects. For example, the IT system collects large amounts of data at any time. Efforts by both the private and public sectors to develop, deploy and educate IT systems are becoming an integral part of raising the transport economy of the country (Liu et al., 2020).

Intelligent Transport systems fundamentally change mobility and communication to transport legislation and vehicle regulation (Sumalee \& Ho, 2018).

\section{Methodology}

The statistical analysis is performed to examine the interrelated indicators of the transport system and IT systems. The research carried out using this method notice the change of the transport system indicators over several years and to identify the problems that have arisen in the transport system of Vilnius. It is possible to determine whether the IT systems used in Vilnius impact safety, traffic jams, and pollution.

Strength, Weakness, Opportunity, and Threat (SWOT) analysis makes it possible to identify the strengths, weaknesses, opportunities, and threats of the object in question to carry out activities effectively and implement change. The Strength, Weakness, Opportunity, and Threat analysis shows the advantages and disadvantages of the object, indicating the possibilities and threats of problem-solving. Strength, Weakness, Opportunity, and Threat analysis are helpful to find out which changes are needed and knowing opportunities and threats lead to effective decisions.

The Cost-Benefit analysis is performed to evaluate the Automatic Incident Detection (AID) system of Vilnius in Transport Control Center suggested implementing by the authors. Firstly, the implementation cost and the system are calculated, and then the income is predicted using three scenarios: optimistic, pessimistic, and realistic.

The research is carried out in stages (collecting information, research of indicators, analysis of data, presentation of conclusions) using statistical analysis of transport system indicators of Vilnius and SWOT analysis. The study evaluates IT system in Vilnius, review their benefits, and developing. 


\section{Analysis of transport system indicators and implemented Intelligent Transport systems in Vilnius}

This chapter presents the analysis of IT systems applied in Vilnius and the problems they solve. The statistical data analysis was performed to investigate the interrelated indicators of the transport system and IT systems. This method shows the change in the transport system indicators over several years and identifies the problems that have arisen in the transport system of Vilnius. It is possible to determine whether the IT systems used in Vilnius work and change safety, traffic congestion, the efficiency of the transport system and pollution.

\subsection{Statistics of road accidents}

In the National Transport Development Programme 2014-2022 the importance of IT systems is highlighted, and the need for security infrastructure measures is pointed. The Traffic Management Center of Municipality Enterprise "Susisiekimo paslaugos" collects daily data on traffic accidents in Vilnius (time, place, direction, source of information).

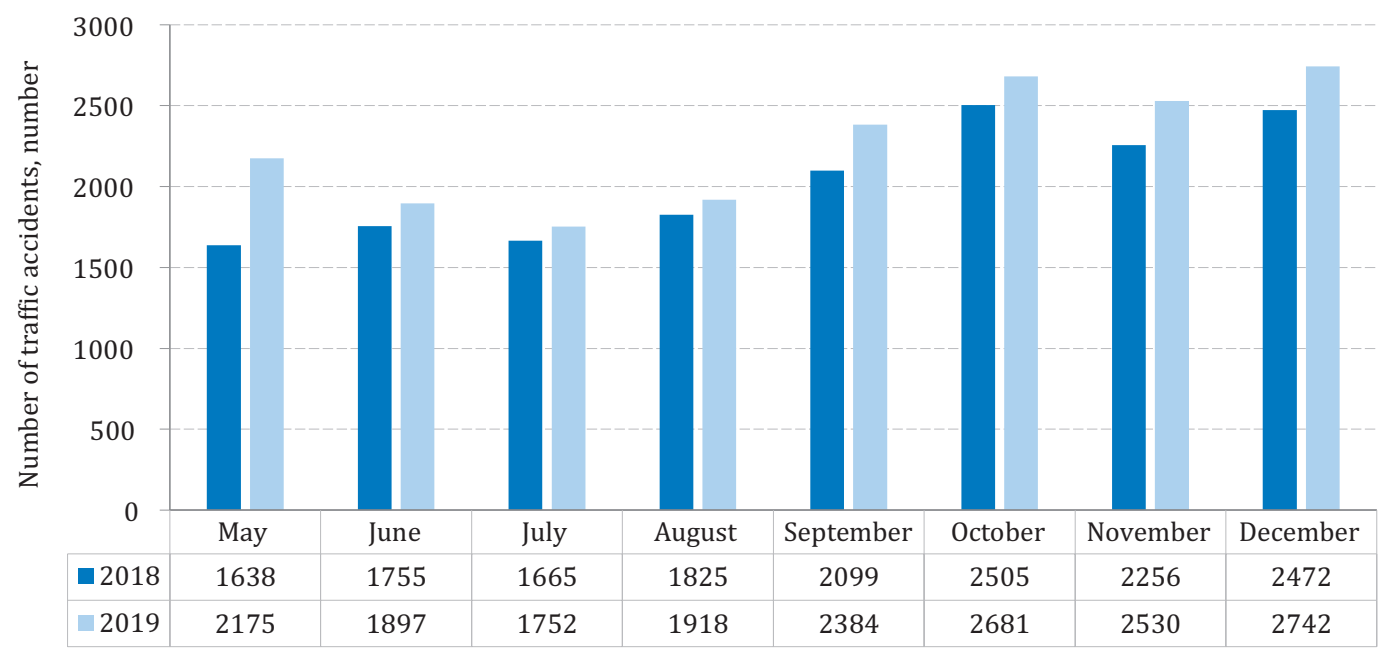

Note: compiled by authors.

Figure 1. The number of traffic accidents in 2018 and 2019 May-December comparison 
Traffic incidents are recorded when seen through the cameras and when they have been marked on the Waze map or notified by the radio station.

The bar chart of traffic accidents in Vilnius in 2018 and 2019 from May to December was created (Figure 1). 2019 May-December there were 1864 traffic accidents more than in 2018 in Vilnius. Compared to 2018, the total accident rate of Vilnius in 2019 May-December increased by $11.5 \%$.

The statistical data analysis showed that in 2019 there was the highest number of fatal accidents on Vilnius streets. A total of 20 fatal accidents on the roads in 2016. In 2017 there were 19 fatal accidents on the road, in 2018 - 16, in 2019 - 22 (Figure 2). The number of fatal accidents on the roads of Vilnius in 2019 was $10.0 \%$ higher than in 2016, 15.8\% higher than in 2017, and 37.5\% higher than in 2018.

Based on valid Traffic Statistics in Lithuania, traffic accidents lead to losses in the state economy. As stated in the data statistics from the Lithuanian Road Administration under the Ministry of Transport and Communications, it is clear that in 2018 the average damage to the Lithuanian economy due to a person killed on the road was 591538 EUR. In 2019 due to 22 people killed on the roads of Vilnius, the Lithuanian economy suffered a loss of 13013836 EUR.

The number of traffic accidents in Vilnius is growing every year - in 2019, there was the highest number of fatalities compared to 2016-2018. Every road accident that kills a person causes damage to the Lithuanian economy. Damage suffered in 2019 amounted to 13.01 million EUR (Figure 3). Consequently, specific solutions are needed to reduce the number of accidents and people affected by them.

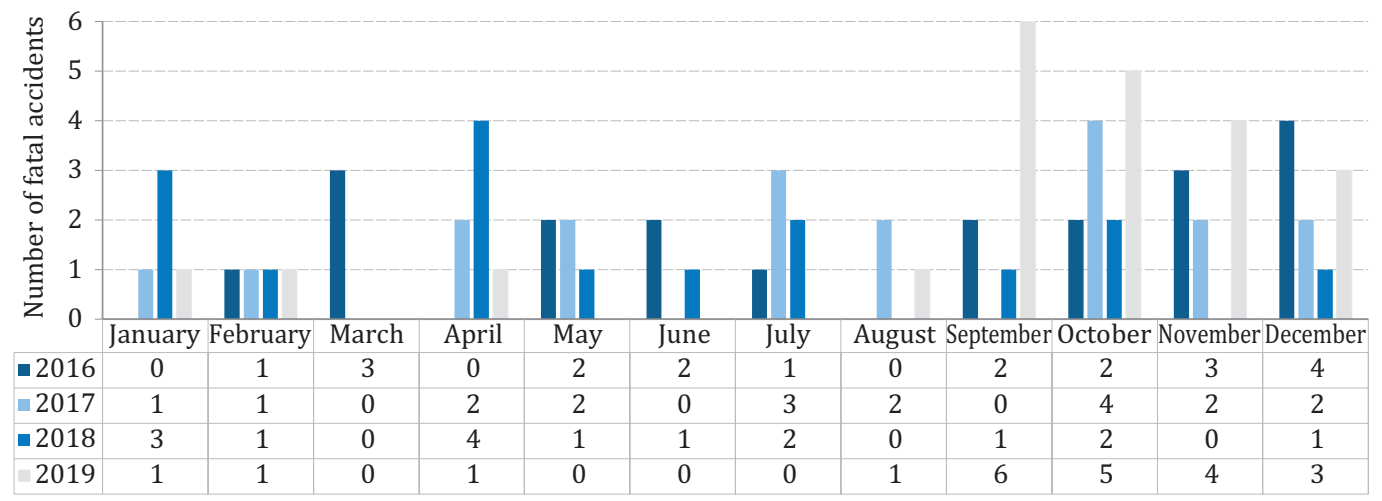

Note: compiled by authors.

Figure 2. Changes in the number of fatal accidents on Vilnius streets 


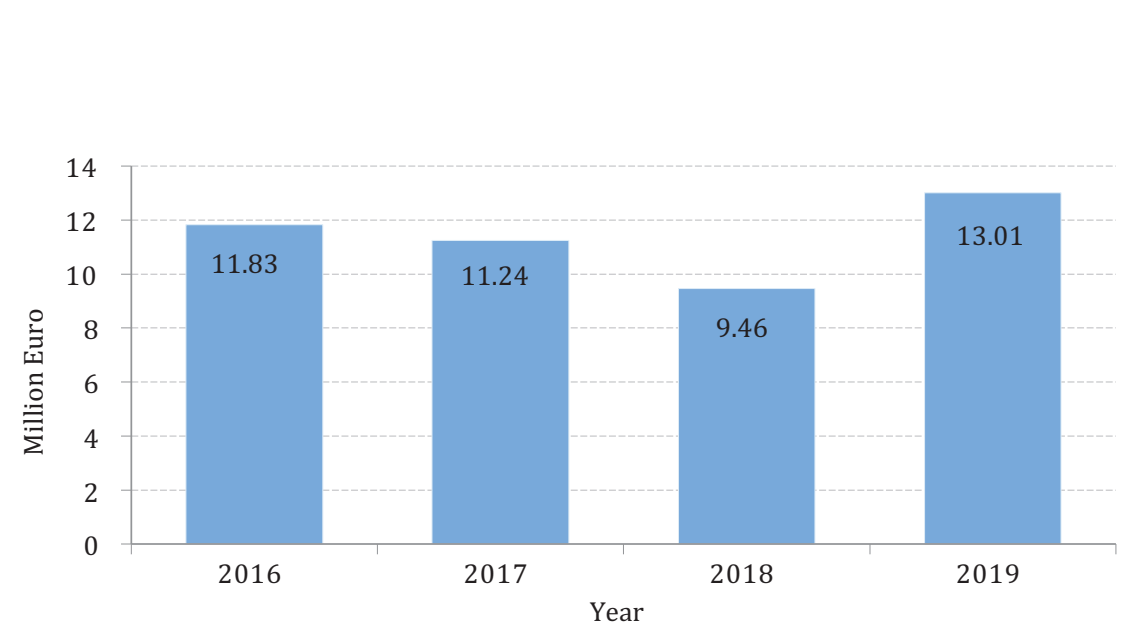

Note: compiled by authors.

Figure 3. The damage to the Lithuanian economy due to fatal accidents

\subsection{Analysis of vehicle flows and congestion duration}

The traffic management department constantly monitors the change in traffic flows and makes appropriate traffic management decisions. Municipality Enterprise "Susisiekimo paslaugos" identified the most intense intersections in Vilnius and compiled a traffic volume map to inform the population (Figure 4). It depicts fifty intersections where car traffic in 2016-2019 was the busiest.

In 2017 congestion was caused by many vehicles (93.6\%), 3.3\% traffic jams caused by traffic accidents, $0.9 \%$ - because of road works and $2.2 \%$ - due to intersection blocking, uneven traffic flow. It is estimated that congestion costs are an average of 480 million EUR per year in Vilnius (Mačiulis, 2016).

In agreement with Hartman (2017) and Debczak (2018), traffic jams cause negative social consequences and affect the economy and the environment. Drivers involved in traffic jams are often intolerant, tend to behave aggressively, and threaten road users working on busy streets (Hartman, 2017). Traffic jams also have a negative impact on the environment - increase environmental pollution and noise.

Thus, traffic jams affect the economy, social environment, ecology, and traffic jam cost in Vilnius are about 480 million EUR/year.

\subsection{Analysis of pollution and noise indicators}

Based on the Lithuanian Road Police Office data, the transport sector emits about $30 \%$ of total $\mathrm{CO}_{2}$ emissions in the European Union. 


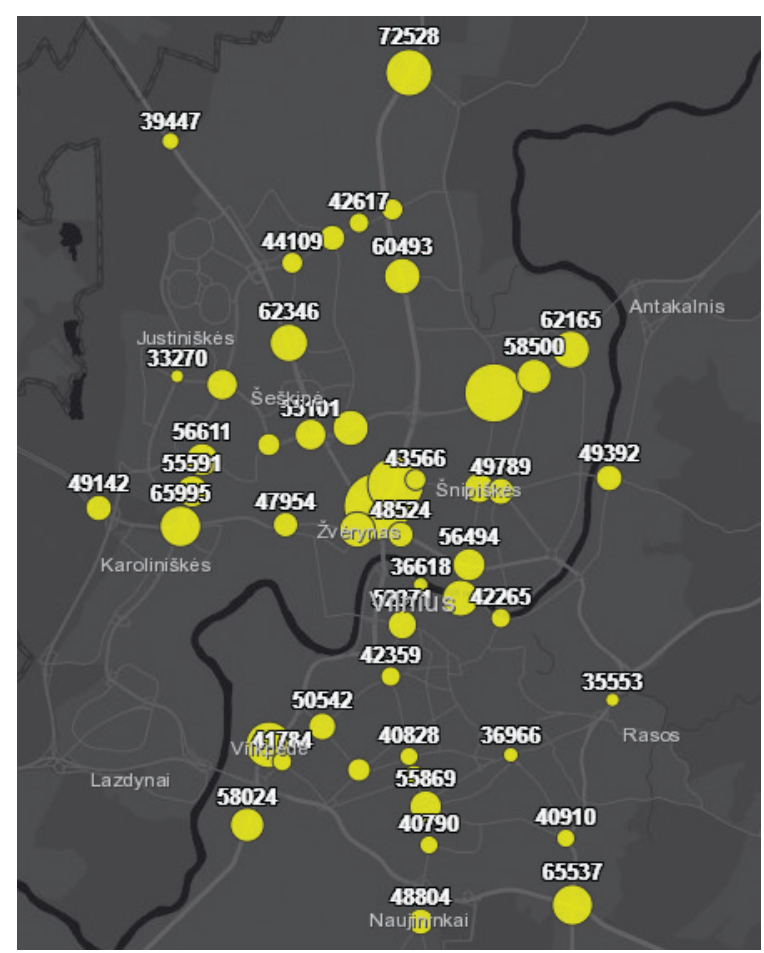

Figure 4. The map of intersections with high traffic volume in 2019 (portal.sisp.lt)

Seventy-two per cent of this amount is emitted by road vehicles. The increasing number of road vehicles and older cars are leading to an increase in pollution and noise. Based on the Sustainable Urban Mobility Plan data, about 29\% of all cars in Vilnius have the Euro3 standard, which leads to higher pollution and noise. It is stated that the pollution in $6 \%$ of Vilnius territories is higher than the highest safe indicator. In 20191.3 million of 1.5 million (87\%) of cars registered in Lithuania emit more than $130 \mathrm{~g} / \mathrm{km}$ of $\mathrm{CO}_{2}$. Two hundred seventy-three thousand nine hundred fifty-seven vehicles, travelling one kilometre, emit about 35.6 thousand $\mathrm{kg}$ of greenhouse gases in Vilnius. It is unclear how $\mathrm{CO}_{2}$ emissions affect human health and how much economic damage they cause.

Pollution is a problem in the transport system caused by many vehicles, old cars and negatively affects human health and the environment. The busiest streets of Vilnius are the most polluted. In Vilnius County, vehicles emit about $35.6 \mathrm{~kg}$ of $\mathrm{CO}_{2}$ per kilometre. 


\section{Overview of Intelligent Transport systems in Vilnius}

When dealing with congestion and accidents in Vilnius, it is important to discuss IT system types. Intelligent Transport systems are rapidly implemented and improved in the transport infrastructure of Vilnius. The number of IT systems installed in Vilnius is growing every year. The entire traffic management system consists of 289 controlled intersections with 1885 traffic flow detectors and 983 sensor buttons for pedestrians and cyclists. There are also 105 video surveillance cameras in the city, 18 speed measuring devices, 13 electronic scoreboards for information on traffic and one variable information road sign.

\subsection{SITRAFIC scala}

In March 2020, there are 289 controlled intersections in Vilnius. They operate based on existing traffic flows in real-time. These controlled intersections are managed and operated in the Traffic Management Center using the SITRAFFIC software. SITRAFFIC software used for traffic control in Vilnius monitors the operation of controlled intersections. It allows changing the operating modes of intersections to reduce air pollution and increase traffic safety.

\subsection{Traffic detectors}

Traffic detectors are installed in each traffic lane of the controlled intersection. Sensors detect vehicles at intersections or pedestrians at crossings, and their operation is monitored in the SITRAFFIC Scala program. Traffic data collected by traffic detectors are stored in the system and used for traffic volume analysis, traffic organisation planning based on the TrafficVision software.

\subsection{Video surveillance system}

This system is equipped to monitor the traffic situation in real-time accurately. As a result, Traffic Management Centre operators rapidly respond to atypical traffic situations, obstacles on the roads, and congestion. Municipality Enterprise "Susisiekimo paslaugos" installed 105 video surveillance cameras in Vilnius (Directive 2010/40/EU...). Fiftyfour per cent of cameras have a control function, and $46 \%$ of them are without a control function.
A Cost-Benefit

Analysis

of the Installation of an Automatic Incident Detection System in Vilnius 
The video surveillance cameras installed in Vilnius capture approximately $4.83 \%$ of all road traffic accidents per year. Cameras increase safety and security in Vilnius.

\subsection{Recording devices for traffic offences}

These are speed measuring devices, red light cameras and bus lane cameras based on the TrafficVision software. These devices are designed to reduce accident rates in Vilnius because they discipline drivers, encourages compliance with road traffic rules. The Automatic Traffic Offender Recording system also frees up Bus lanes and prioritises public transport, thus reducing the travel time of public transport passengers.

\subsection{Variable information road signs}

This variable information road sign is an electronic panel where the set images change. The first variable information road signs based on the TrafficVision software were installed in Vilnius in 2019 at one of the busiest intersections crossed by an average of 83064 vehicles per weekdays (Saturdays or Sundays are not included in the statistics due to the need for more efficient traffic management.

The methodology for traffic volume calculation is used in solving traffic safety problems on roads. Therefore, in Chapter 4, these methods are described in more detail, statistical analysis of traffic volume change inroads of national significance, main, national, and regional roads are provided.

\section{Methods of calculating averages of traffic volume}

The following calculations are made for all the roads of national significance:

The annual average daily traffic (AADT, vpd) of total traffic volume, freight transport and every vehicle class on the road sections, roads, and road groups; the average daily traffic volume estimated every quarter (quarterly $T$ ) of total transport flow and freight transport flow; the average daily traffic volume estimated every month (monthly $T$ ) of total transport flow and freight transport flow; the average daily traffic volume estimated daily (daily $T$ ) of total transport flow and freight transport flow; distribution of traffic volume per day (provided for every hour as a percentage of a daily $T$ ). 
This chapter is showed the $A A D T$ about total traffic volume, freight transport and every vehicle class on the road sections, roads, and road groups and the method of calculating traffic for a month.

\subsection{Method of calculating the annual average daily traffic on the road section}

Based on the data of stationary permanent traffic accounting posts, is calculated by using Equation (1):

$$
A A D T=\frac{1}{365} \sum_{d=1}^{355} D T, \mathrm{vpd},
$$

where $A A D T$ - annual average daily traffic, vpd; $D T$ - daily traffic, vpd; 365 - number of days in a year.

Based on the data of stationary periodical posts, where accounting is done four times a week, and temporary posts (except for the ones where measurements are made once a year), is calculated following the "Methodology for Calculation of the Annual Average Daily Traffic from Temporary Measurement Data” (Jarašūnienė \& Miliauskaitė, 2011). The same methodology is used when data is based on temporary costs (except those where measurements are made yearly).

Based on the data of stationary periodical posts where traffic accounting is done twice a year for a week, $A A D T$ is calculated by using the data of the adjacent section with a permanent post. By application of this method, based on the measurements of each of two weeks, an individual $A A D T$ estimation is calculated $-A A D T_{1}$ and $A A D T_{2}$. The final estimation result is calculated based on the following Equation (2):

$$
A A D T=\frac{1}{4}\left(3 A A D T_{1}+A A D T_{2}\right), \mathrm{vpd},
$$

where $A A D T$ - annual average daily traffic at the examined post, vpd; $A A D T_{1}$ - estimation of the $A A D T$ based on the measurement data of the week that does not include the period of June-August, vpd; $A A D T_{2}$ estimation of the $A A D T$ based on the measurement data of the week that includes the period of June-August, vpd.

Traffic accounting once a year is done only at those sections, next to which at one of the adjacent road sections, the accounting is done periodically or constantly. At those road sections $A A D T$ is calculated following this procedure:

- the proportion of traffic volume among road sections is established;

- based on the data of periodical or permanent post, $A A D T$ is calculated; of the Installation of an Automatic Incident Detection System in Vilnius 
- at other road sections, $A A D T$ is calculated based on the established traffic volume proportion.

At road sections where traffic accounting is uncalculated in the current year, is calculated by multiplying the value of $A A D T$ of the previous year by the traffic volume change coefficient in that road group to which the road under examination belongs (Equations (3)-(5)):

- main road section

$$
I_{M_{\text {current year }}}=p_{M} \cdot I_{M_{\text {previous year }}},
$$

- national road section

$$
I_{N_{\text {current year }}}=p_{N} \cdot I_{N_{\text {previous year }}},
$$

- regional road section

$$
I_{R_{\text {current year }}}=p_{R} \cdot I_{R_{\text {previous year }}},
$$

where - $A A D T$ at the road section in the current year, vpd; $I_{R_{\text {previous year }}}$ $A A D T$ at the road section in the previous year, vpd; $p_{M}, p_{N}, p_{R}-$ traffic volume change in the main, national, and regional roads, respectively (the current year as stated in the data by static, permanent post data: $p_{M}=1.088, p_{K}=1.054, p_{R}=1.036$ ) (Jarašūnienė \& Miliauskaitė, 2011).

\section{Implementation of Automatic Incident Detection system in Vilnius - a cost-benefit analysis}

The analysis of the scientific literature, the analysis of statistical data, and the review of IT systems show that the application of IT systems is important to reduce accident rates, congestion, and other transport system problems. This article presents the implementation of the AID system in Vilnius and presents the financial evaluation.

Automatic Incident Detection is an innovative system that combines the functions of several different IT systems: video surveillance cameras, automated traffic light control systems, electronic scoreboards for traffic information. The system constantly monitors traffic, collects data, processes information. When an accident, roadblock or congestion is detected, a signal to the operator of Traffic Management Center is sent, offering to select one of the prepared messages to be automatically posted on the relevant variable message sing, select the most suitable traffic signal program. When AID is used, information on the exact location of the accident is provided more quickly, identify potential congestion, inform road users about the situation, and make appropriate traffic regulation decisions to reduce travel time, noise, and pollution, 
avoid additional accidents. Moreover, AID registers offenders of Road of the Installation Traffic Rules, i.e. drivers on Bus lanes.

The calculation of the income provided by the AID system in monetary of an Automatic Incident Detection System in Vilnius terms assesses the benefits provided by the system. The first benefit is a reduction in the number of fatal accidents. Video surveillance cameras capture $4.8 \%$ of all traffic accidents in Vilnius. In 2019 there were 22 fatal accidents. In 2019 there were 22 fatal accidents, and a video surveillance camera captured one of them. The ambulance arrives at the accident, and the death of an injured person is avoided. The average damage to the economy due to a person killed on the road is 591538 EUR. This amount of money is saved by the installed AID system in Vilnius.

The second benefit is a reduction in the duration of congestion. It was found that $3.34 .8 \%$ of all traffic accidents in Vilnius of traffic jams in Vilnius occur or their duration is prolonged because of traffic accidents. Every year in Vilnius, people spend 240 million hours in traffic jams (Mačiulis, 2016). Thus, 792 thousand hours are spent in traffic jams due to traffic accidents. The added value of one working hour is 20 EUR (Mačiulis, 2016). It is possible to calculate saving costs by reducing the duration of traffic jams in Vilnius.

The third benefit of the AID system is recording the offenders of Road Traffic Rules - drivers who drive on Bus lanes. The number of offenders at the time of each scenario was determined based on the statistics of existing recording devices for traffic offences. It was calculated that it is possible to record 3408 offenders per year. It is possible to measure the benefits of the system.

At first, when calculating the payback of an automatic accident recording system, the costs of the system maintenance after installation are unused. Thus, only the installation value is used - 578000 EUR. This amount includes the cost of purchasing and installing the system, salaries for staff involved in the project, advertising costs.

\subsection{Optimistic scenario}

Table 1. Economic benefits of Automatic Incident Detection in an optimistic scenario per year

\begin{tabular}{lc}
\hline \multicolumn{1}{c}{ Economic benefits } & Total, EUR \\
\hline \multicolumn{1}{c}{ Saved human life } & 591538 \\
Time spent by a person in congestion was reduced by $0.03 \%$ & 475200 \\
3408 offenders paid the full amount of the fine & 51122 \\
(the total amount of the fine - EUR 30; 50\% of the sum & \\
is returned to the budget of Vilnius Municipality) & 1117860 \\
\hline
\end{tabular}


Suppose the average income received each year is the same and equals 1117860 EUR/year (Table 1). The values of the payback period calculations during the optimistic scenario are shown in Table 2.

Table 2. Calculation of installation payback time in an optimistic scenario

\begin{tabular}{|c|c|c|c|c|c|c|}
\hline \multirow{2}{*}{$\begin{array}{c}\text { Estimated } \\
\text { financial } \\
\text { flows }\end{array}$} & \multicolumn{6}{|c|}{ Year } \\
\hline & 1 & 2 & 3 & 4 & 5 & 6 \\
\hline $\begin{array}{l}\text { Residual } \\
\text { value, EUR }\end{array}$ & 578000 & 0 & $\mathrm{O}$ & $\mathrm{O}$ & 0 & $\mathrm{O}$ \\
\hline $\begin{array}{l}\text { Revenue, } \\
\text { EUR }\end{array}$ & 1117860 & 1117860 & 1117860 & 1117860 & 1117860 & 1117860 \\
\hline $\begin{array}{l}\text { Expenditure, } \\
\text { EUR }\end{array}$ & 496096 & 499032 & 573732 & 573732 & 573732 & 573732 \\
\hline $\begin{array}{l}\text { Gross profit, } \\
\text { EUR }\end{array}$ & 621764 & 618828 & 544128 & 544128 & 544128 & 545160 \\
\hline $\begin{array}{l}\text { Operating } \\
\text { result, EUR }\end{array}$ & 43764 & 618828 & 544128 & 544128 & 544128 & 545160 \\
\hline
\end{tabular}

Note: compiled by authors.

In the optimistic scenario, the value of the benefits of the AID system is positive from the first year after the installation. In this case, one death on the roads of Vilnius is avoided every year and 23760 working hours saved, and significant profit made.

\subsection{Pessimistic scenario}

Table 3. Economic benefits of Automatic Incident Detection in a pessimistic scenario per year

\begin{tabular}{lc}
\hline \multicolumn{1}{c}{ Economic benefits } & Total, EUR \\
\hline Saved human life & 591538 \\
Time spent by a person in congestion was reduced by 0.003\% & 47520 \\
3408 offenders paid half amount of the fine (EUR 15) & 25561 \\
Total revenue & 664619 \\
\hline
\end{tabular}

Suppose the average income received each year is the same and equal to $664619 \mathrm{EUR} /$ year (Table 3). The values of the payback period calculations during the optimistic scenario are shown in Table 4. 
Table 4. Calculation of installation payback time in a pessimistic scenario

\begin{tabular}{lcccccc}
\hline \multicolumn{1}{c}{$\begin{array}{c}\text { Estimated } \\
\text { financial } \\
\text { flows }\end{array}$} & $\mathbf{1}$ & $\mathbf{2}$ & $\mathbf{3}$ & $\mathbf{4}$ & $\mathbf{5}$ & $\mathbf{6}$ \\
\cline { 2 - 7 } & 578000 & 409477 & 243890 & 153003 & 62116 & 0 \\
\hline $\begin{array}{l}\text { Residual } \\
\text { value, EUR }\end{array}$ & 664619 & 664619 & 664619 & 664619 & 664619 & 664619 \\
$\begin{array}{l}\text { Revenue, EUR } \\
\text { Expenditure, }\end{array}$ & 496096 & 499032 & 573732 & 573732 & 573732 & 573732 \\
$\begin{array}{l}\text { EUR } \\
\text { Gross profit, } \\
\text { EUR }\end{array}$ & 168523 & 165587 & 90887 & 90887 & 90887 & 90887 \\
$\begin{array}{l}\text { Operating } \\
\text { result, EUR }\end{array}$ & -409477 & -243890 & -153003 & -62116 & 28771 & 90887 \\
\hline
\end{tabular}

Note: compiled by authors.

In the pessimistic scenario, the value of the benefits of the system is positive only in the fifth year after the installation. In that case, one death is avoided every year on the roads of Vilnius, 2376 of working hours saved, and a profit of 28771 EUR is obtained in the five years of operation.

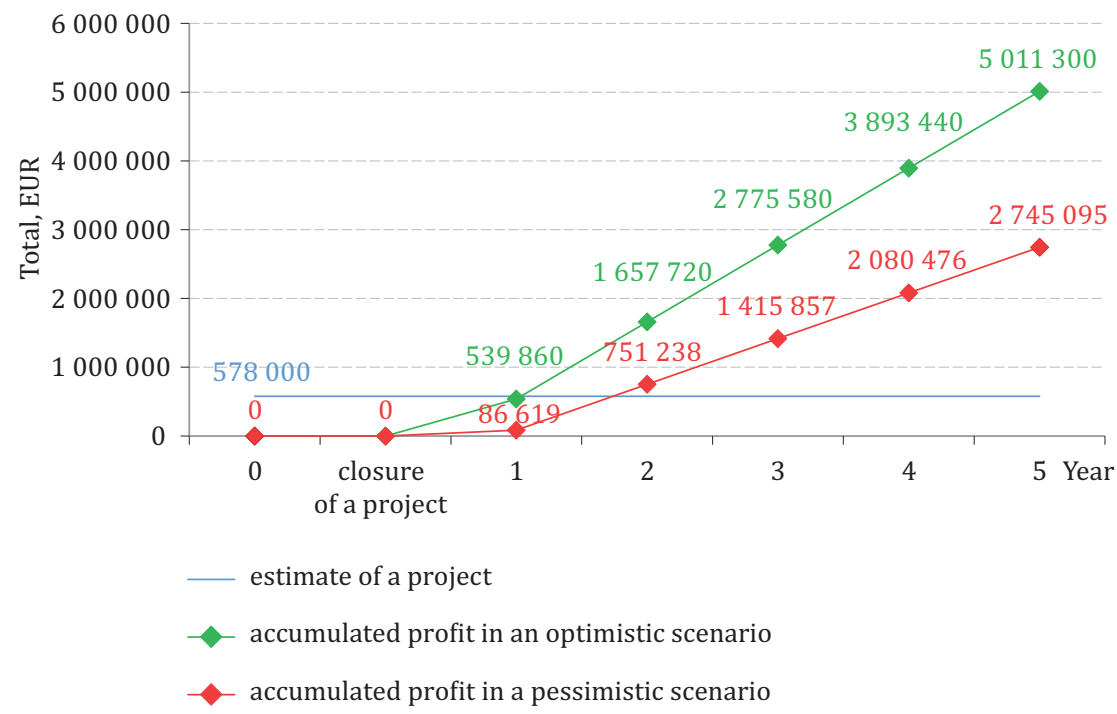

Note: compiled by authors.

Figure 5. The line chart of the implementation payback
A Cost-Benefit Analysis of the Installation of an Automatic Incident Detection System in Vilnius 
The project estimates and the values of the accumulated profit in optimistic and pessimistic scenarios are used to create the implementation payback line chart.

The graph (Figure 5) shows the year the project pays off (when the accumulated profit equals to estimate the project). In the optimistic scenario, the project pays off in the first year after its closure. The project pays off almost at the end of the second year. The actual payback time of the project, regardless of the maintenance costs, is one and a half years after the closure of the project.

However, when calculating the payback of the system, the costs incurred after the closure of the project must also be considered. For this reason, the cost of cameras, further maintenance of the AID system and salary paid to employees working with the system after the closure of the project are included. The total price of purchase, installation, and maintenance of the AID in the first year - 1074096 EUR. In the second year, only the maintenance of the system (498 000 EUR) and the salary for the employee (1032 EUR) is paid. When the warranty period expires (after 24 months), and software depreciation is assessed, the cost of maintaining the system and cameras increase by $15 \%$ and amount to $573732 \mathrm{EUR} /$ year. A period of five years is taken to calculate the payback of the project. The project estimates and the values of the accumulated profit in the case of optimistic and pessimistic scenarios

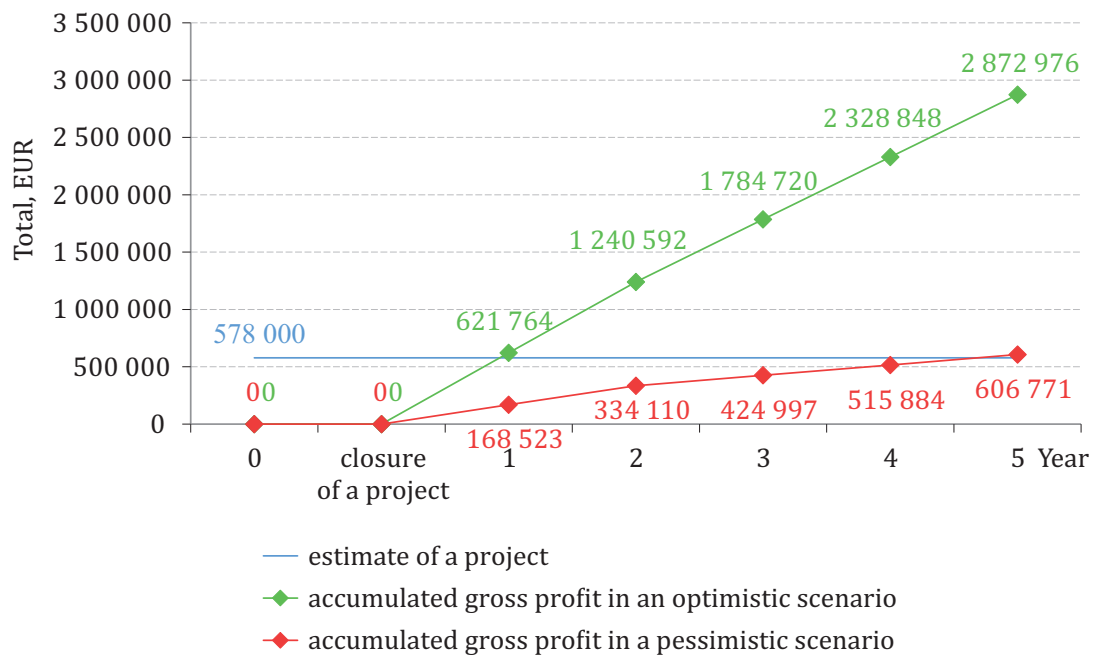

Note: compiled by authors.

Figure 6. The chart of the implementation payback after estimating operating costs 
are used when compiling the payback schedule of the implementation. The costs incurred for the maintenance of the system are considered.

The graph (Figure 6) shows the year the project pays off after estimating the operating costs (when the accumulated gross profit equals estimate the project).

In the optimistic scenario, the project pays off for the first year after its closure. The project pays off almost at the end of the fifth year. The actual payback time of the project, considering the maintenance costs, is almost three years after the closure of the project.

\subsection{Value created by the benefits of the Automatic Incident Detection}

Neither the results of the optimistic nor the pessimistic scenarios show the real benefits of AID. In a realistic scenario, the potential benefits of the system were assessed to anticipate its benefits (Table 5).

Table 5. The economic benefits of the system in a realistic scenario over the year

\begin{tabular}{lc}
\hline \multicolumn{1}{c}{ Economic benefits } & Total, EUR \\
\hline Saved human life & 591538 \\
Half of the 3408 offenders paid the total amount of the fine & 38342 \\
(EUR 30), the other half-half amount of the fine (EUR 15) & \\
Total revenue & 772440 \\
\hline
\end{tabular}

In a realistic scenario, the value of the benefits of an AID is positive in the third year after installation (Figure 7). In that case, one death is avoided every year on the roads of Vilnius, 7128 of working hours saved, and a profit of more than 170000 EUR is obtained from the third year after installation.

An automatic accident recording system also benefits employees of the Traffic Management Center and General Assistance Center. As a result, they have more time to devote to other jobs, thus increasing the productivity of companies. Also, it is possible to adjust the system parameters in various ways

Implementing the system provides direct and indirect benefits to Lithuania, Vilnius city, residents, workers. The total value created by the project benefits is at least 811000 EUR over five years. Assessing the system in the future, adjusting, and improving its performance Possibly reduces congestion, prevent more road deaths, reduce pollution and noise, improve the efficiency of the transport system, and increase the safety of road users. of the Installation of an Automatic Incident Detection System in Vilnius 


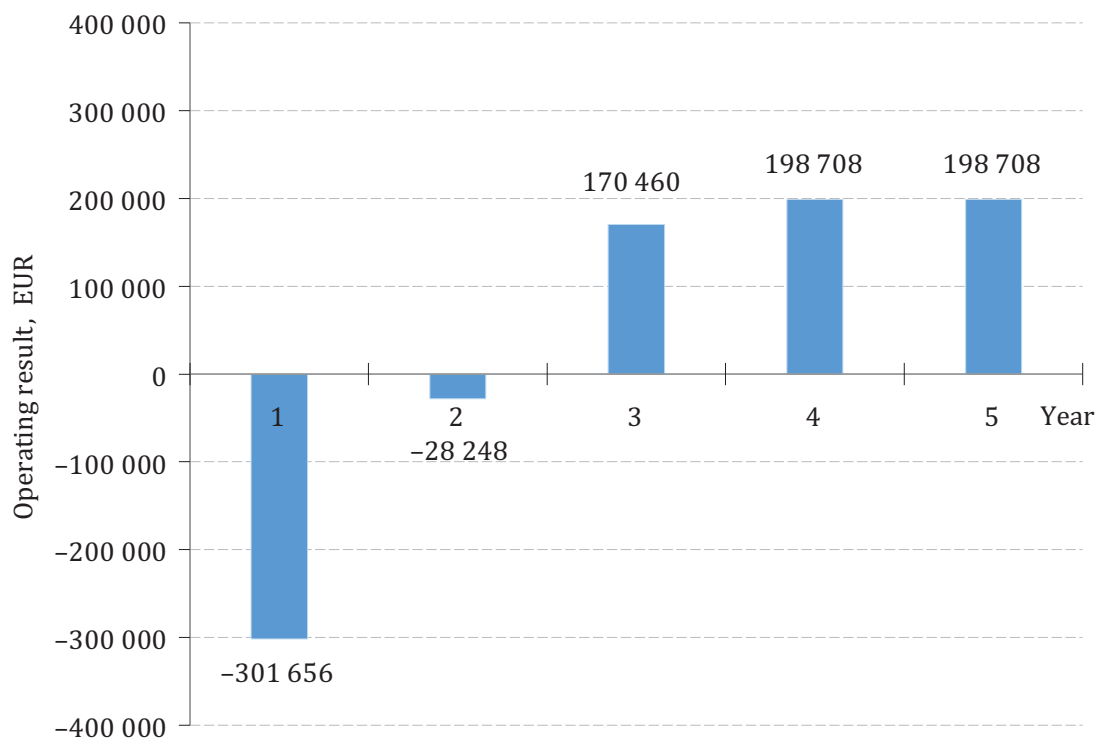

Note: compiled by authors.

Figure 7. Change in operating result in a realistic scenario

\section{Conclusions}

1. The analysis of the scientific literature has shown that the main benefits of Intelligent Transport systems are related to problems in transport systems. The application of Intelligent Transport systems leads to reduced congestion, accident rate and pollution, help to manage traffic and increase the efficiency of the transport system.

2. The analysis of statistics on the Vilnius transport system revealed that accidents, congestion, pollution, and noise are the problems of the Vilnius transport system, which appeared due to many vehicles, insufficient Intelligent Transport systems installed in Vilnius transport system. These problems have a negative impact on the economics and social environment.

3. It has been found that the average damage to the Lithuanian economy due to one death on the road is 591538 EUR. Due to congestion, the city of Vilnius suffers about 480 million EUR economic damage. It has been found that registered vehicles in Vilnius County emit about 35.6 thousand $\mathrm{kg} \mathrm{CO}_{2}$ per $\mathrm{km}$. 
4. Intelligent Transport systems help increase traffic management efficiency and reduce problems in the transport system.

5. The authors of the article presented the evaluation of the implementation of the Automatic Incident Detection system in Vilnius. The system is worth installing because only programming is required, and the cost of purchasing and installing the system is commensurate with the quality and benefits provided. The implementation of the system saves 591538 EUR per year due to the saved human life. Congestion time is also projected to decrease by $0.009 \%$ per year and save 142560 EUR. As congestion decreases, vehicle pollution and noise in Vilnius also decrease. It has been determined that the total benefit provided by the system amounts to at least 811000 EUR per year.

\section{REFERENCES}

AIndra Labs (2019). What is Intelligent Transportation System (ITS): Applications and Examples.

Ambrazevičius, A. (2008). Lietuvos transporto sistema. Vilnius: Generolo Jono Žemaičio Lietuvos karo akademija.

Debczak, M. (2018). Here's how much traffic congestion costs the world's biggest cities. Mental Floss.

Directive 2010/40/EU of the European Parliament and of the Council of 7 July 2010 on the framework for the deployment of Intelligent Transport Systems in the field of road transport and for interfaces with other modes of transport

Hartman, D. (2017). The effects of traffic congestion. In azcentral.com

Haseeb, J. (2017). Definition, Objectives and Importance of ITS. In aboutcivil.org

Hofmeister, P., \& Kadner, M. (2011). Performance Impacts through Intelligent Transport Systems: an Assessment of how to Measure and Evaluate.

Janušová, L., \& Čičmancová, S. (2016). Improving safety of transportation by using intelligent transport systems. Procedia Engineering, 134, 14-22. https://doi.org/10.1016/j.proeng.2016.01.031

Jarašūnienè, A., \& Miliauskaitė, L. (2011). Application of measures addressing traffic safety issues on Lithuanian roads. In Proc. of 15th International Conference "Transport Means", Kaunas University of Technology, Kaunas. 139-142.

Liu, Y., Bao, R., Tao, J., Li, J., Dong, M., \& Pan, C. (2020). Recent progress in tactile sensors and their applications in intelligent systems. Science Bulletin, 65(1), 70-88. https://doi.org/10.1016/j.scib.2019.10.021

Mačiulis, N. (2016, May). Kiek kainuoja eismo spūstys? In diena.lt (in Lithuanian)

National Research Council (US), Committee on Science, Technology for Countering Terrorism. Panel on Transportation, National Research Council, Transportation Research Board Staff, National Research Council (US), Committee on Science, \& Technology for Countering Terrorism of the Installation of an Automatic Incident Detection System in Vilnius 
(2002). Deterrence, Protection, and Preparation: the New Transportation Security Imperative (Vol. 270). Transportation Research Board.

Paulauskas, R., Bernhard, O., Glemža, A., Nabil, A. R., Kapočius, J., Docka, P., \& Mickaitis, G. (2011). Intelektiniu (pažangiu) transporto sistemu igyvendinimo Lietuvoje galimybiu studija. Galutinè ataskaita. Lietuvos Respublikos susisiekimo ministerija, Vilnius. (in Lithuanian)

Perallos, A., Hernandez-Jayo, U., Onieva, E., \& Zuazola, I. J. G. (Eds.). (2015). Intelligent Transport Systems: Technologies and Applications. John Wiley \& Sons.

Rodrigue, J. P., \& Notteboom, T. (2020). Transportation and Economic Development. The Geography of Transport Systems (5th ed.). Routledge. https://doi.org/10.4324/9780429346323

Roncoli, C., Papageorgiou, M., \& Papamichail, I. (2015). Traffic flow optimisation in presence of vehicle automation and communication systems-part II: optimal control for multi-lane motorways. Transportation Research Part C: Emerging Technologies, 57, 260-275. https://doi.org/10.1016/j.trc.2015.05.011

Sotra, M. (2017). 7 Smart City Solutions to Reduce Traffic Congestion.

Sumalee, A., \& Ho, H. W. (2018). Smarter and more connected: future intelligent transportation system. Iatss Research, 42(2), 67-71. https://doi.org/10.1016/j.iatssr.2018.05.005

Sumra, I. A., Hasbullah, H., \& bin Ab Manan, J. L. (2013). Classification of traffic system in Intelligent Transportation System (ITS). Modern Traffic and Transportation Engineering Research, 2(4), 1-10. 